\title{
Loan Service Application
}

\author{
Kirthi, Balaji Pradeep, Murali Krishna Kodavati, Rajani Katiyar
}

\begin{abstract}
In the past few years, much activity has been carried out in developing the Web-Service based, bank Application system. The important work performed by this system is the optimization and enhancement of the existing system. The bank uses a different technology for maintaining the loan of the customer; it uses the MYSQL database for storing the data and other specific software for the loan service process. The security of the client's information during the transaction is of prime importance. The credit risk is analyzed by the system before approval of the loan, apart from these different factors influence the asset structure of the bank. Spring boot is used to develop the loan service application. Postman is used to get the response. The loan servicing application provides the Customer with complete information about the process of loan and its management as mentioned in this paper.

Keywords: credit risk, database, asset structure, security
\end{abstract}

\section{INTRODUCTION}

Earlier loan service was traditionally given by big banks but nowadays even smaller bank gives loan. So there is a need to manage the service provided by the banks. There is increased development in the economy and the technology, which leads to the increased requirements of the online application. The bank provides loan to the customers to manage their personal and other requirements [1]. Meanwhile, the bank doubts about the repayment the loan by the customer i.e., there is a credit risk also associated with the loan process [2].Loan servicing refers to the organizational function of a bank, which keeps the record of a loan from the time of issue to the client until its repayment. It maintains the record of transaction details such as amount of loan taken by the customer /client, method of repayment and the duration of its repayment. On the other hand, security is an important step in any online service application. It is the main requirement for all online financial applications. For example, data privacy, customer trust, and long term growth all depends on security of the financial application. Hence, for this reason any financial organization or the bank which provides the loan has to develop astrong security system [3]. The loan servicing application is used for carrying out the process of loan and its repayment in a proper way.

Revised Manuscript Received on June 15, 2020.

* Correspondence Author

Kirthi*, RV College of Engineering Bengaluru

kirthiec.ec16@rvce.edu.in

Balaji Pradeep, Altimetrik Bengaluru bpradeep@altimetrik.com

Murali Krishna Kodavati, Altimetrik Bengaluru mkodavati@altimetrik.com

Rajani Katiyar, RV College of Engineering Bengaluru rajanikatiyar@rvce.edu.in

(C) The Authors. Published by Blue Eyes Intelligence Engineering and Sciences Publication (BEIESP). This is an open access article under the CC BY-NC-ND license (http://creativecommons.org/licenses/by-nc-nd/4.0/)
This application has a feature to carry out the functions such as sending notification of the payment and setting the remainder for the next payment, along with that it also the sends monthly payment statements, maintains the records of payments and the balances. Loan servicing function is not only carried out by the bank and financial institution which issues the loans, but it is also carried out by a non-bank entity specialized in loan servicing.

Earlier loan servicing was the core function of the banks. At that time, banks were issuing the original loan, and they were responsible for handling the process of the loan starting from its issue till its repayment. Earlier loans and mortgages in particular were used as securities and a bank book was provided. Here the servicing of loans proved to be a less profitable than the origination of new loans.

To overcome this, the loan servicing part of the bank was separated from origination and opened up to the market. It gives the record-keeping burden of loan servicing and the changing habits and expectations of borrowers, to the company which uses software like loan servicing application to solve the problem in the issue of loan and its repayment. Kafka is used to display the payment success or failure message.

\section{FACTORS INFLUENCING THE ASSET STRUCTURE OF BANK}

1. The first factor is Technology, which is the most important factor which is responsible for the changes in the financial sector. The development of technology includes the use of various service applications such as loan service application which eliminates the geographical boundaries and provides service to its customer [4].

2. The second factor is that the presence of demanding clients. Because only the

Increasing demand from a client or a customer can enable a bank to use developed technologies, different service applications to attract the client and provide him /her with services that are easy to use.

2. The third factor is the globalization and the increasing competition from different national and international institutions affect the market of the online financial service application [4]. The optimization of the asset structure, maintenance of the assets and their profitability can make banks competitive in the market.

Published By:

Blue Eyes Intelligence Engineering

DOI: 10.35940/ijeat.E9253.069520

Journal Website: $\underline{\text { www.ijeat.org }}$

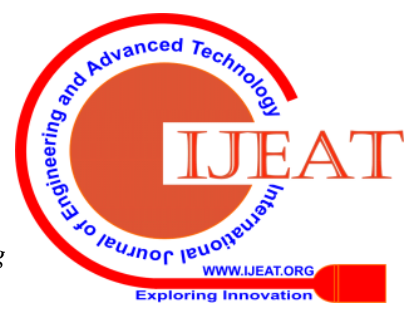




\section{Loan Service Application}

\section{BANK LOAN PROCESS}

In any organization such as banks and or financial institution the improvement of bank loan process is of prime importance [6].And it requires following procedures.

1. Examining the existing bank process:

Whenever the new user/customer wants to use the application to carry out the loan process, the customer has to register then carry out the further process. Registration includes the personal details for the user/customer such as Name, phone number, address, email-id, government identity proof(Adhaar card, pan card etc) etc. Figure 1 shows the flow of the application If the customer has an account in the application then the customer can direct login into the application using login credentials to carry out the transaction. The flowchart explains the work flow of existing process.

\section{Changing existing processes}

Due to the security issues and overload of accounts in the existing system, changes have to be made in the application/system to carry out the loan servicing process smoothly, hence new technology should be introduced which could handle the overload of accounts and for the security new data security process should be developed.

3. Developing new processes

To handle the overload of account, data should be pushed to the cloud and for security of the data during transaction or during transfer there is a probability of data destruction, to overcome these problem strong encryption techniques should be introduced.

\section{USES:}

1. Reducing the time required for the implementation of loan process By using the loan service application the client/customer can reduce the loan application procedure

i.e. manual filling of application, submission of required documents, access the ability of the customer before approving the loan in the banks.

2 Reduction of implementation time: As all the procedure is online with the use of specific software such as loan servicing application. The approval of loan requires less time through online as compared to manual approval of loan.

3. Improvement of quality: This application provides complete information about different type of the loan such as education loan, business loan, home loan, personal loans etc. It also provides the feature such has help desk, query section, which helps the customer to better understand the process before selecting the required options

\section{WORKING OF THE APPLICATION}

This application is divided into 3 parts: Database layer, service layer and front end layer. Spring boot framework is used for developing the application. The security is provided by using the inbuilt dependency present in spring boot known as spring security.

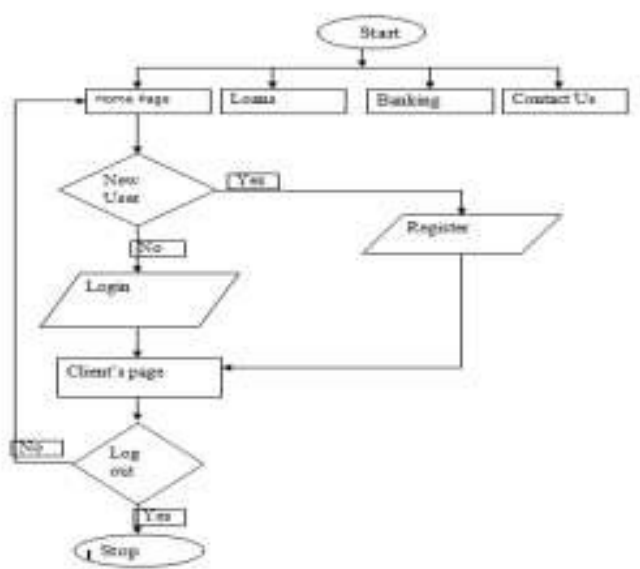

Figure 1: Flowchart of existing loan process page

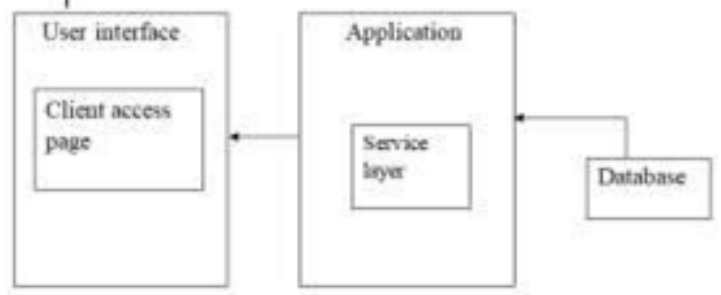

Figure 2: Layers of loan service application\

1) Database layer: It includes storing the data in the database, or mocking the data from the data warehouse, by using specific software. It includes the transaction details such as, date of issuing the loan, amount of loan issued, period of loan repayment, method of repayment, amount repaid till date and the remaining loan amount that has to be repaid. The user profile details, such as the name of the client, contact number, bank account number, any government authorized identity card for the proof. All these information of the client are stored in the database.

2) Service layer: This layer contains all the services which is provided by the bank, i.e. checking whether the transaction is complete, whether it was successful or not, based on the conditions set in the services layer, the clients gets the notifications of payments.

2.1 Database: It refers to the data structure which stores the organized information. As the bank needs to store huge amount of client's information hence Database management system(DBMS) is designed for storing and

retrieving the stored data, when required, for quick access for the bank and

clients. It also provides the clients to select the repayment methods.

\subsection{Methods to Repayment of loan are:}

1. Equal payments

2. Equal installments

3. One time payments

4. Recurring payments

5. Fixed equal payments

6. Installment-free period

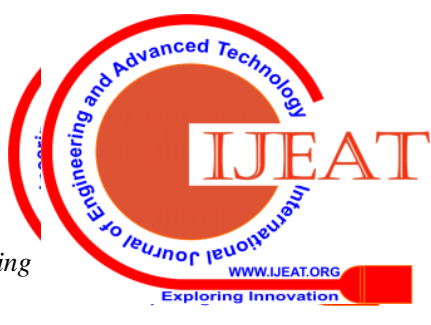


3) Front end Layer (User Interface): It displays the content of the application to the user and gives access for the user to through the different options given in that page. It provide the user with different options such as registration, login, creating a user profile, applying for the loan, method of payment and balance to be repaid.

\section{RESULTS}

Spring boot application is used to develop the loan service application, the backend development where the customer's payment details are stored in the database. Using the dependency provided by spring boot the application can be developed with the features which we want to incorporate. When the customer's makes the payment success or failure message is displayed. Figure: 3 Shows the output of payment.

The details of the customer's are stored in the database so that when the customer needs to know the details of his/her loan, it can be viewed. When the payment of loan is completed a status message is such as success or failure, which helps the customer to know his/her payment status. And conditions are written in the code to check the loan amount taken and amount paid in the installments. Postman is used to view the responses

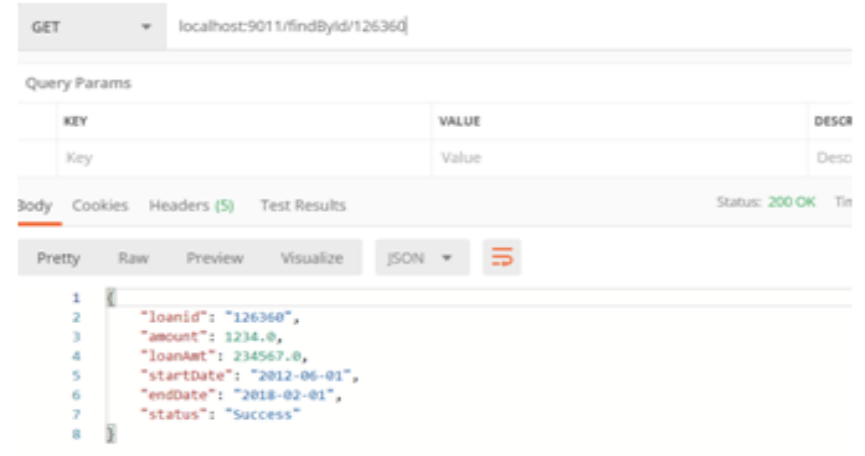

Figure 3: payment details

Using Kafka messaging system the payment completion whether it was completed successfully or the payment failed to complete the transaction is displayed automatically when the customer completes the transaction. Figure 4 shows the Kafka message when payment was successful

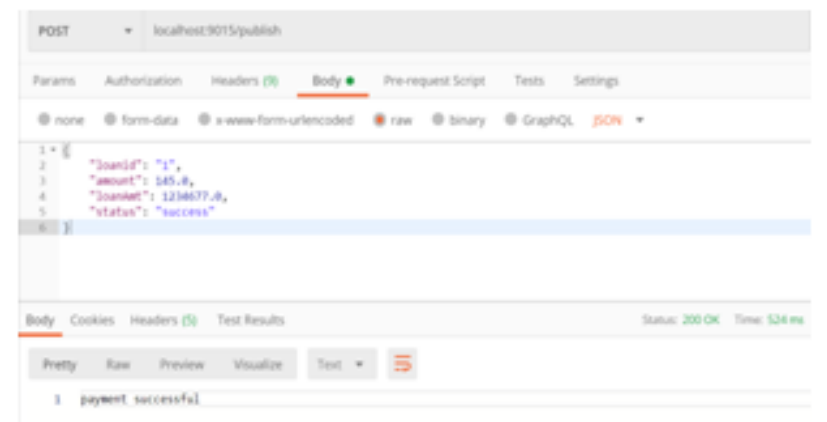

Figure 4 Kafka message on the payment completion

Exceptional handling is performed here so as to ensure that the customer is entering the valid loan id before making the payment when the customer enters the invalid loan id exception is thrown to ensure the he/se doesn't proceed to make the payment until the customer enter the valid loan id. Figure 5 shows the exception

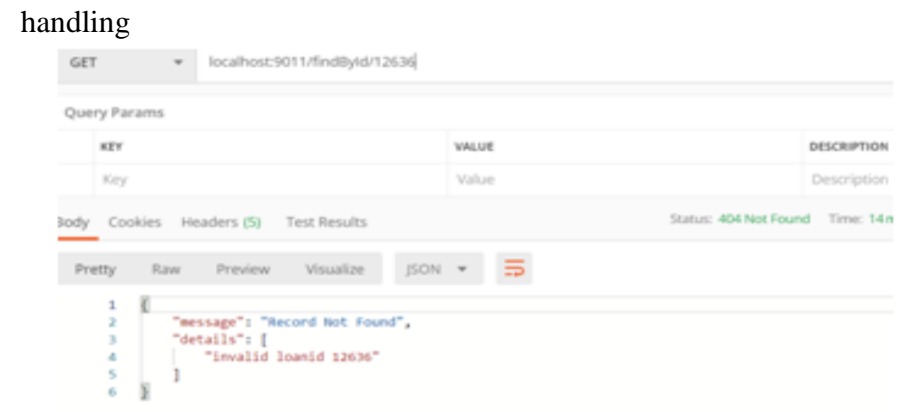

Figure 5 exception handling

The loan details of the customer has the loan details of the customer such as in how many payments the customer is going the pay the entire loan and how many pending payments to made etc.

Figure 6 loan details of the customer

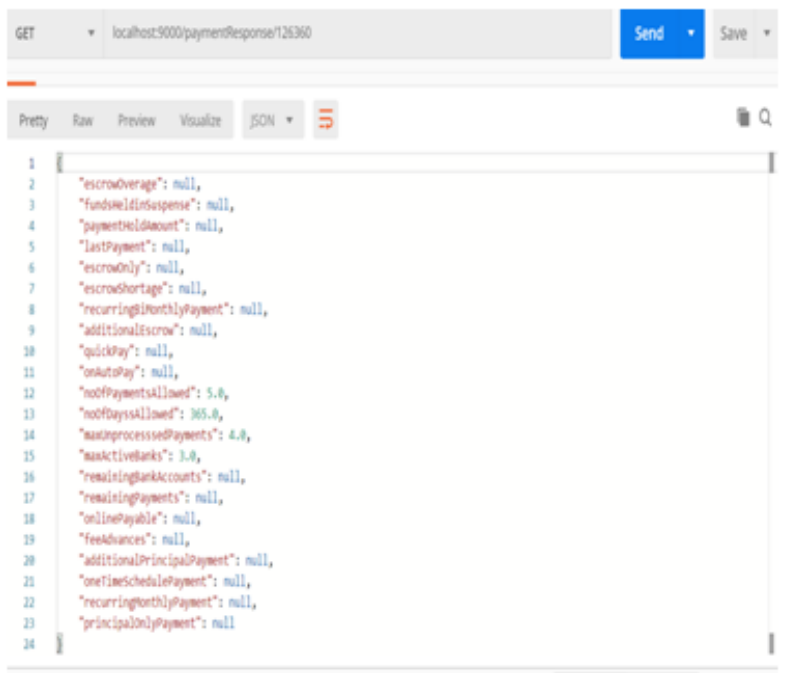

Figure 6 shows the loan details

\section{CONCLUSION}

From this paper, it is possible to know that loan service application can help the client or customer in understanding the procedure of getting the particular loan as early as possible when compare to the manual filling of application in the bank for loan. As the service application is provided with the features such as security- encryption, credit risk analysis, data storage of the customer's details in a proper way in the database and getting the details whenever there is need for it.

\section{REFERENCES}

1. A. Çaliş, A. Boyaci and K. Baynal, "Data mining application in banking sector with clustering and classification methods," 2015 International Conference on Industrial Engineering and Operations Management (IEOM) , Dubai, 2015, pp. 1-8.

2. Q. Chen and J. Lin, "Integrating of business intelligence and CRM in banks: An empirical study of SOM applied in personal customer loans in Taiwan,"2015 International Conference on Fuzzy Theory and Its Applications (iFUZZY) , Yilan, 2015, pp. 68-73.

3. Xinhua Dong, Ruixuan Li, Heng He, Wanwan Zhou, Zhengyuan Xue and Hao $\mathrm{Wu}$, "Secure sensitive data sharing on a big data platform," in Tsinghua Science and Technology, vol. 20, no. 1, pp. 72-80, Feb. 2015.

Published By:

Blue Eyes Intelligence Engineering

720 \& Sciences Publication

(C) Copyriaht: All riahts reserved.

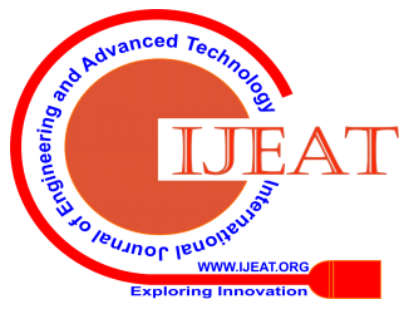




\section{Loan Service Application}

4. S. Saksonova, "Notice of Retraction: Managing banks' asset and loan portfolios," 2011 2nd IEEE International Conference on Emergency Management and Management Sciences, Beijing, 2011, pp. 776-779.

5. E.Ozsoz., E.W Rengifo,M.A Akinkunmi, "What determines return risks for bank equities in Turkey?," Borsa Istanbul Review ,pp.2331,2014.

6. Vinod Kumar L, Natarajan S, Keerthana S, Chinmayi K M and Lakshmi N, "Credit Risk Analysis in Peer-to-Peer Lending System," 2016 IEEE International Conference on Knowledge Engineering and Applications (ICKEA), Singapore, 2016, pp. 193-196.

7. Yanjiang Yang, HaiyanZhu, Haibing Lu,Jian Weng,Youncheng Zhang,Kim-Kwang Raymond Choo, "Cloud based data sharing with fine grained proxy reencryption.Pervasive and Mobile Computing," Elsevier Science Publishers pp122- 134 Volume 28 Issue C, June 2016.

8. G. Wang, J. Hao, J. Ma, H. Jiang, "A Comparative Assessment of Ensemble Learning for Credit Scoring," Expert System with Applications, vol. 38, pp. 223-230, 2011.

9. $\quad$ Y. Dong, M.Firth,W. Hou, W. Yang," Evaluating the performance of Chinese commercial banks: A comparative analysis of different types of banks,"European Journal of Operational Research, pp.280-295, 2016.

10. S.Mammadli,"Fuzzy Logic Based Loan Evaluation System," Procedia Computer Sience, , pp.495-499, 31 Dec 2016.

11. Chen Xiaojie, Dong Huailin and Wu Qingfeng, "SCAD algorithm and its application in analyse of bank loan,"2009 4th International Conference on Computer Science \& Education, Nanning, 2009, pp. 1934-1939.

12. Y. Yanbing and L. Bin, "Bayes' Rule and Bank Credit Game Risk Analysis,"2013 Fifth International Conference on Measuring Technology and Mechatronics Automation, Hong Kong, 2013, pp. 335-337.

13. Y. Ma and H. Liu, "Research of SVM Applying in the Risk of Bank's Loan to Enterprises,"2010 2nd International Conference on Information Engineering and Computer Science, Wuhan, 2010, pp. 15.

14. R. Cole et al., "Principles for the Management of Credit Risk," Basel Committee on Banking Supervision, Basel, 26 p., September 2000.

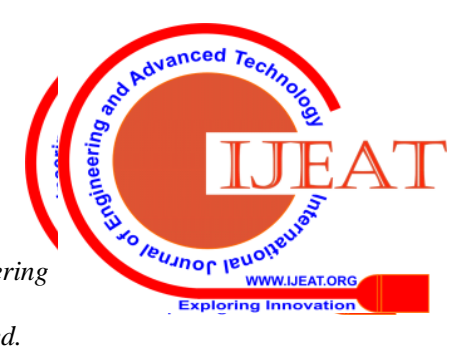

